\title{
Comparison of treatment response to intravitreal injection of triamcinolone, bevacizumab and combined form in patients with central retinal vein occlusion: A randomized clinical trial
}

\author{
Ghader Motarjemizadeh ${ }^{1}$, Miaad Rajabzadeh ${ }^{2}$, Naser Samadi Aidenloo ${ }^{3}$ Rohollah Valizadeh ${ }^{4}$
}

${ }^{1}$ M.D., Assistant Professor, Department of Ophthalmology, Faculty of Medicine, Urmia University of Medical Sciences, Urmia, Iran

${ }^{2}$ General Practitioner, Faculty of Medicine, Urmia University of Medical Sciences, Urmia, Iran

${ }^{3}$ M.D., Associate Professor, Department of Ophthalmology, Faculty of Medicine, Urmia University of Medical Sciences, Urmia, Iran

${ }^{4}$ MSc Student of Epidemiology, Student Research Committee, Department of Epidemiology, Urmia University of Medical Sciences, Urmia, Iran

\section{Type of article: Original}

\begin{abstract}
Background: Central retinal vein occlusion (CRVO), is the second-most common disorder after diabetic retinopathy that threatens the vision related to retinal vessels. One of the main reasons of vision loss is CRVO in acute and chronic forms.

Objective: The aim of this study was to investigate the response to intravitreal injection of triamcinolone, bevacizumab, and a combined form in patients with CRVO.

Methods: This study was a double-blinded randomized clinical trial conducted on patients with CRVO who were referred to the ophthalmology clinic of Urmia Imam Khomeini Hospital from May 2015 to May 2016. In total, ninety patients were divided into three groups using random numbers table. The first group received intravitreal triamcinolone acetonide (IVT) for treatment of macular edema due to CRVO, the second group received intravitreal bevacizumab (IVB) and the third group received a combination of IVT and IVB. The best corrected visual acuity (BCVA) and central macular thickness (CMT) were recorded and analyzed using optical coherence tomography system.

Results: In this study a total of 90 eyes were studied, 41 case $(45.55 \%)$ were male and 49 cases $(54.44 \%)$ were female. The mean age of patients was $68.41 \pm 8.32$ years. The mean score of final visual acuity was $0.293 \pm 0.11$ in the IVT group, $0.25 \pm 0.10$ in the IVB group and $0.48 \pm 0.15$ in the IVB+IVT group. The differences between groups considering final visual acuity was significant $(\mathrm{p}<0.001)$. The mean thickness of final macular was $383.33 \pm 97.70$ micrometer in IVT group, $386.33 \pm 136.79$ micrometers in IVB group and $307.33 \pm 110.79$ micrometers in IVT + IVB group which were significant $(\mathrm{p}=0.014)$.

Conclusion: Using a combination of bevacizumab and triamcinolone in the treatment of central retinal vein occlusion compared with using each of them separately, had a better result and can be used as a solution in this disease.

Trial registration: The trial was registered at the Thai Registry of Clinical Trials (http://www.clinicaltrials.in.th) with the TCTR ID: TCTR20170612005.

Funding: The authors received no financial support for the research, authorship, and/or publication of this article. Keywords: Bevacizumab, Intravitreal Injections, Retinal Vein Occlusion, Triamcinolone
\end{abstract}

\section{Introduction}

Central retinal vein occlusion (CRVO), is the second-most common disorder after diabetic retinopathy (1). One of the main reasons of vision loss is CRVO in acute and chronic forms. There are many risk factors associated with

\section{Corresponding author:}

Naser Samadi Aidenloo, Department of Ophthalmology, Faculty of Medicine, Urmia University of Medical Sciences, Urmia, Iran. Tel: +98.9141454412. Fax:+98.4333469929, Email: n.samadiadnl@gmail.com

Received: May 01, 2017, Accepted: June 17, 2017, Published: August 2017

iThenticate screening: June 11, 2017, English editing: July 18, 2017, Quality control: August 02, 2017

(C) 2017 The Authors. This is an open access article under the terms of the Creative Commons Attribution-NonCommercialNoDerivs License, which permits use and distribution in any medium, provided the original work is properly cited, the use is non-commercial and no modifications or adaptations are made. 
CRVO including age, hypertension, diabetes mellitus, retinal artery atherosclerotic changes, open-angle glaucoma and hyperopia (2). Its prevalence increases with age and varies from $0.1 \%$ to $5 \%$. Visual acuity is a reflection of the severity of the disease, retinal macular hemorrhage, cystoid macular edema and ischemia (3). Macular edema is one of the fundamental causes of vision loss in chronic and acute CRVO as well as ischemic and non-ischemic forms (4). CRVO study showed that although the macular network photocoagulation decreased angiographic edema, the vision did not improve (3). Recently, the standard treatment for central retinal vein occlusion was limited to photocoagulation for neovascular adverse effects and there was no solution to macular edema (3). The main trigger for the formation of edema and macular neovascularization in patients with CRVO is the production of vascular endothelial growth factor (VEGF (caused by hypoxia, which is an angiogenic factor, causing angiogenesis and increase of vascular permeability (5). It has been shown that vascular endothelial growth factor increases in eyes with CRVO (6). Some studies, as noted, have shown that the injection IVB and injection of IVT have beneficial effects for these cases. However, due to their half-life, repeated injections are required (22). Studies did not have the same results on the effectiveness and safety of these therapies in CRVO, and so, this shows the importance of this study in the world. Thus, the aim of the study was to compare the effectiveness of IVT and IVB separately and combined, for the treatment of patients with CRVO, to obtain the best choice.

\section{Material and Methods}

This study was a double-blinded randomized clinical trial conducted on patients with CRVO who were referred to the ophthalmology clinic of Urmia Imam Khomeini Hospital from May 2015 through May 2016. In total, ninety patients were divided into three groups using a random numbers table. The first group received IVT $2 \mathrm{mg}$ for treatment of macular edema due to CRVO, the second group received IVB $1.25 \mathrm{mg}$ and the third group received a combination of IVB $1 \mathrm{mg}$ and IVT $1.5 \mathrm{mg}$. All injections were carried out by one ophthalmologist after prep and drape of eye if interest in the special room of eye ward. Inclusion criteria were patients with CRVO and satisfaction to participate in the study. Exclusion criteria were the need to use macular photocoagulation in the treatment process, and intravitreal injection of any drug affecting IVB and IVT. This study had some confounding factors including systemic inflammatory disorders such as autoimmune disease, systemic risk factors, such as hypertension, diabetes, systemic vascular disease, glaucoma, hypercoagulable states, dyslipidemia, and elevated plasma levels of homocysteine, concomitant ocular pathology, e.g., diabetic retinopathy or glaucoma, vitrectomy, history of cataract surgery, contraindications for bevacizumab or triamcinolone and pregnancy.

This study was approved by the Ethics Committee of Urmia University of Medical Science (ID code: IR.UMSU.REC.73950114), and the objectives of the study were explained to all participants, and all of them agreed to participate and were assured of the confidentiality of their individual information as well as the voluntary nature of participating in the study. All patients were informed about the protocol of our study and written informed consent was taken. The goals of the study were explained to all participants and all of them agreed to participate and were assured considering the confidentiality of their individual information as well as the voluntary nature of participating. The best corrected visual acuity (BCVA) and central macular thickness (CMT) were recorded and analyzed using optical coherence tomography (OCT). The outcomes were checked at 10 a.m., and considering the blinded nature of this study, neither participants nor analyzer, had any information about the group assigned to the patients. Of a total of 90 patients, 41 patients $(45.55 \%)$ were male and 49 patients $(54.44 \%)$ were female. The mean age of the patients was $68.41 \pm 8.32$ years. The Kolmogorov Smirov was done indicating the normal distribution of the data. The data were analyzed using software SPSS version 21. All data entered into SPSS version 21 software and data as frequency (percentage) and mean \pm SD were reported. ANCOVA (Analysis of Covariance) test was used to compare three groups. Less than 0.05 was considered as the level of significance $(\mathrm{p}<0.05)$.

\section{Results}

In this study, a total of 90 eyes were studied including 30 patients in an IVT injection group, 30 patients in an IVB injection group and 30 patients in a combination of IVT and IVB injection group, 41 cases $(45.55 \%)$ were male and 49 cases $(54.44 \%)$ were female. The mean age of the patients was $68.41 \pm 8.32$ years. The mean score of final visual acuity was $0.293 \pm 0.11$ in the IVT group, $0.25 \pm 0.10$ in the IVB group and $0.48 \pm 0.15$ in the IVB+IVT group. The differences between groups, considering final visual acuity, was significant $(\mathrm{p}<0.001)$. The patients were followed up two times and the mean of BVA was $0.1 \pm 0.05$ micrometer in the IVT group, $482.11 \pm 120.08$ micrometers in the IVB group and $0.34 \pm 0.16$ micrometers in the IVT+IVB group (Table 1). The average of baseline visual acuity was obtained as following, in the IVT group, 301 \pm 0.04 , in the IVB group, $101 \pm 0.04$ and in the IVT + IVB group, $501 \pm 0.05$. The difference between the groups was not statistically significant in terms of baseline visual acuity $(\mathrm{p}=0.968)$ (Table 2). The mean thickness of baseline macular was $480 \pm 107.99$ micrometer in the IVT group, 
$476 \pm 133.17$ micrometers in the IVB group and $490.33 \pm 121.44$ micrometers in the IVT + IVB group which were not significant $(\mathrm{p}=0.895)$ (Table 2$)$. The average of final visual acuity was obtained as following, in the IVT group, $0.293 \pm 0.11$, in the IVB group, $0.25 \pm 0.1$ and in the IVT + IVB group, $0.48 \pm 0.15$. The difference between the groups was statistically significant in terms of final visual acuity $(\mathrm{p}<0.001)$ (Table 2$)$. The average of final macular thickness was $383.33 \pm 97.70$ micrometers in the IVT group, $386.33 \pm 136.79$ micrometers in the IVB group and $307.33 \pm 110.79$ micrometers in the IVT+IVB group, which were significant $(\mathrm{p}<0.014)$ (Table 2). The improvement of final visual acuity and macular thickness compared to baseline in all three groups were shown in Figures 1 and 2.

Table 1. Average of baseline and final of visual acuity and macular thickness in the three groups.

\begin{tabular}{|l|l|l|}
\hline Variable & Mean & SD \\
\hline Baseline visual acuity & 0.1 & 0.05 \\
\hline Baseline macular thickness & 482.11 & 120.08 \\
\hline Final visual acuity & 0.34 & 0.16 \\
\hline Final macular thickness & 359 & 120.66 \\
\hline
\end{tabular}

Table 2. Average of baseline visual acuity, baseline macular thickness, final visual acuity and final macular thickness in the three groups.

\begin{tabular}{|c|c|c|c|c|c|c|c|c|}
\hline \multirow[t]{2}{*}{ Group } & \multicolumn{2}{|c|}{ baseline visual acuity } & \multicolumn{2}{|c|}{$\begin{array}{l}\text { baseline macular } \\
\text { thickness }\end{array}$} & \multicolumn{2}{|c|}{ final visual acuity } & \multicolumn{2}{|c|}{ final macular thickness } \\
\hline & Mean (SD) & $\begin{array}{l}\mathrm{p}- \\
\text { value }\end{array}$ & Mean (SD) & $\begin{array}{l}\mathrm{p}- \\
\text { value }\end{array}$ & Mean (SD) & $\begin{array}{l}\text { p- } \\
\text { value }\end{array}$ & Mean (SD) & $\begin{array}{l}\mathrm{p}- \\
\text { value }\end{array}$ \\
\hline IVT & $\begin{array}{l}0.103 \\
(0.04)\end{array}$ & \multirow[t]{3}{*}{0.968} & $480(107.99)$ & \multirow[t]{3}{*}{0.895} & $\begin{array}{l}0.293 \\
(0.11)\end{array}$ & \multirow[t]{3}{*}{$\begin{array}{l}< \\
0.001\end{array}$} & $383.33(97.70)$ & \multirow[t]{3}{*}{0.014} \\
\hline IVB & $\begin{array}{l}0.101 \\
(0.04)\end{array}$ & & $476(133.17)$ & & $0.25(0.1)$ & & $\begin{array}{l}386.33 \\
(136.79)\end{array}$ & \\
\hline IVB+IVT & $\begin{array}{l}0.105 \\
(0.05)\end{array}$ & & $\begin{array}{l}490.33 \\
(121.44)\end{array}$ & & $0.48(0.15)$ & & $\begin{array}{l}307.33 \\
(110.79)\end{array}$ & \\
\hline
\end{tabular}

\section{Improvement of Visual Acuity}

\section{6}

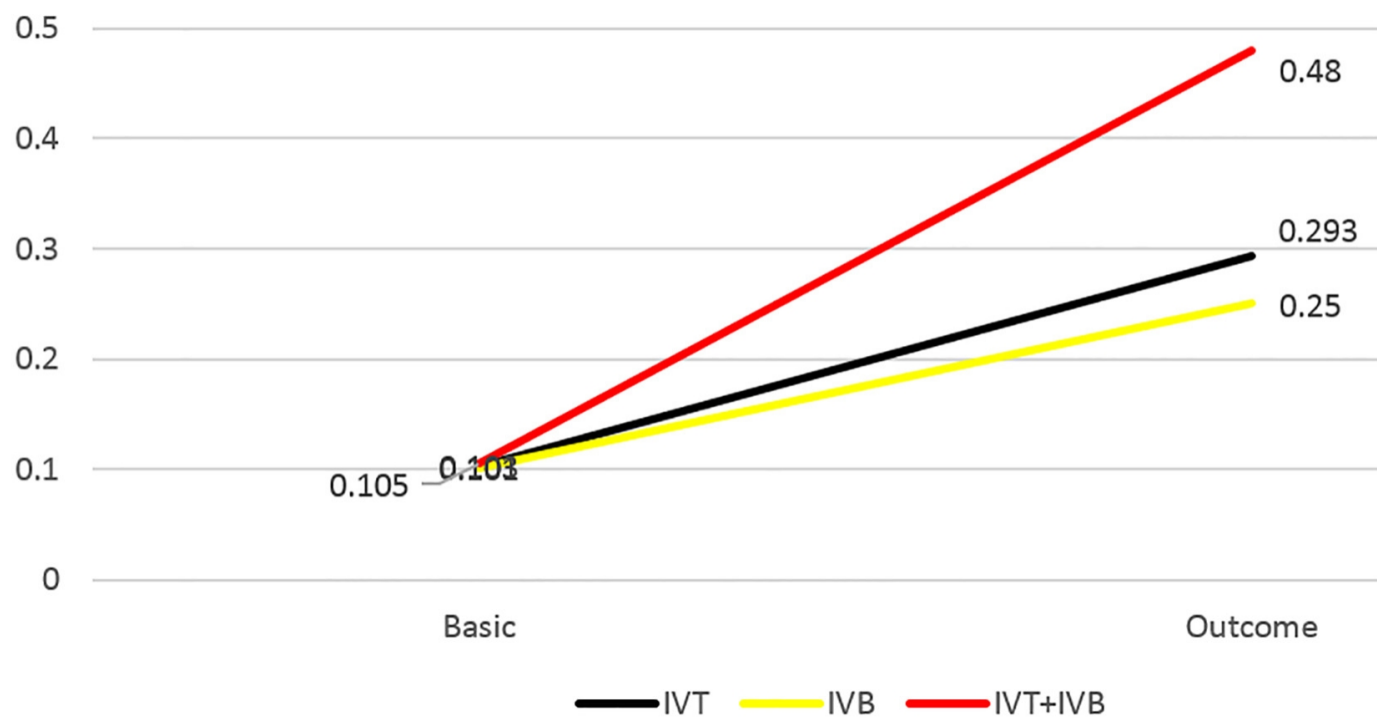

Figure 1. Comparison of improvement rate of visual acuity in the three groups 


\section{Improvement of Macular Thickness}

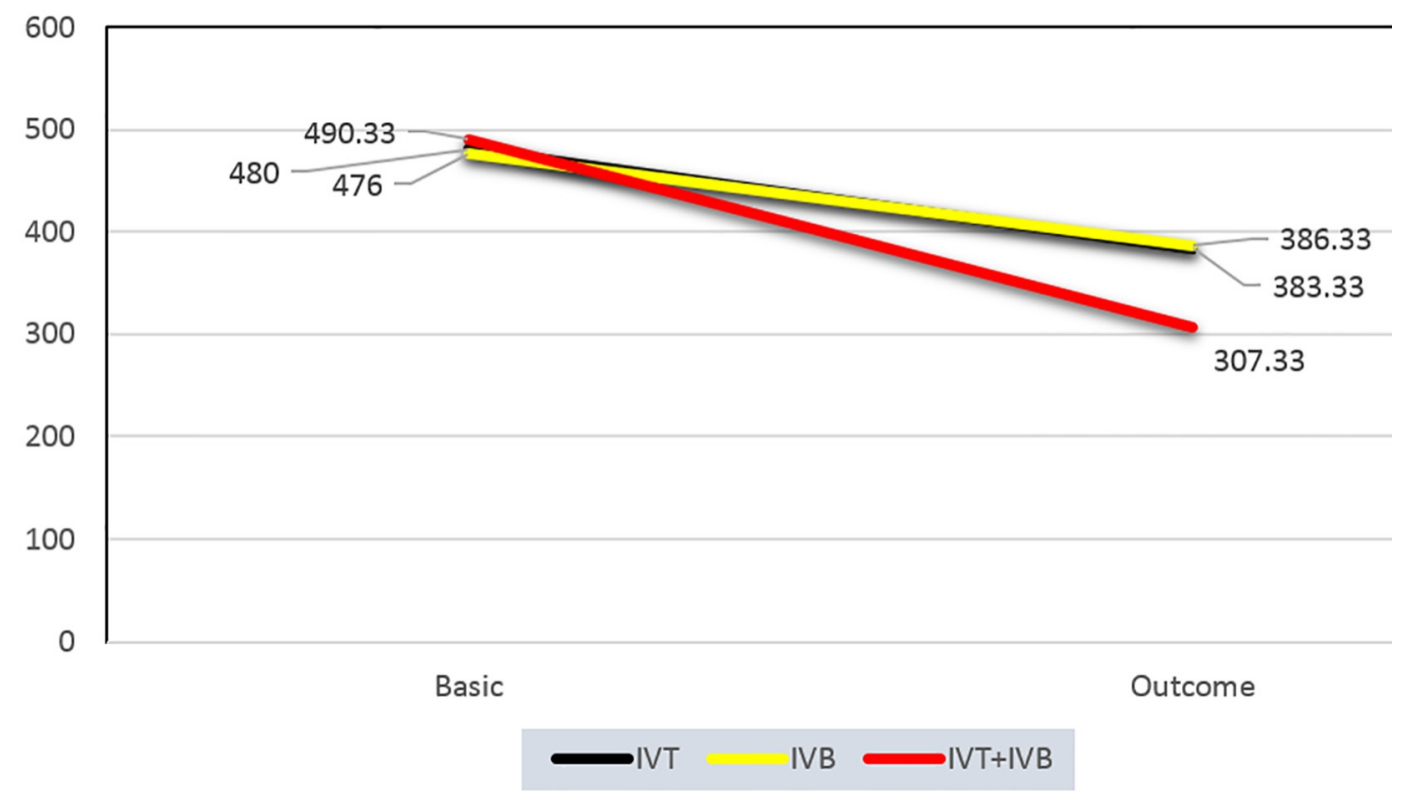

Figure 2. Comparison of improvement rate of macular thickness in the three groups.

\section{Discussion}

Results of analysis of data obtained in this study showed that intravitreal administration of a combination of IVT and IVB drugs, had a greater impact on visual acuity and CMT in the CRVO compared to each of the drugs. During the last ten years, IVT is widely used for the treatment of proliferative diseases, ocular neovascular edematous and central retinal vein occlusion (29). A disproportionate distribution of inflammatory cytokines and antigenic-related retinal vein occlusion has been reported (30) and experimental and clinical studies have showed the temporary impact of the anti-inflammatory effect of triamcinolone in the CRVO (29). The two main complications of IVT are the increase of intraocular pressure and cataracts caused by steroid injections (31-34). Instead, studies of bevacizumab by Rosenfeld et al, and another researcher have showed the improved visual acuity and decrease in macular thickness, and only minor complications in patients with CRVO have demonstrated (35-38). The rise of anti-VEGF compounds caused significant progress in the treatment of various diseases of eyes. VEGF-A has various effects on physiological and pathophysiological processes such as the vascular permeability, chemotaxis, inflammation and mythogenesis (39). VEGF stimulates neovascularization, and is a crucial factor for the creation of blood vessels and neuron cells (40). On the one hand, hypoxia and oxygen free radicals are known as agents for the stimulation of VEGF and on the other hand, there are low levels of the VEGF in the context of epithelium pigment of the retina $(39,41)$. All VEGF isoforms are possible using bevacizumab and ranibizumab. There is evidence supporting the theory that the use of selective inhibitor of VEGF-165 isoforms can be the means for reducing the pathological effects while maintaining its normal physiological function (42). Thus, according to available evidence, the use of each of these treatments alone, the more probable the harms and risks can be expected for the patients. So, in this study, effects of a combination of the drugs were compared with each of these drugs alone. In the study by Ekdawi et al., the authors reported a CRVO resistant to monotherapy bevacizumab or triamcinolone which the combination therapy of triamcinolone and bevacizumab resulted in an improvement in visual acuity and central macular thickness (43), and this study confirmed that the two-drug treatment was better. In another study of Ehrlich et al, the authors suggested that the combination of bevacizumab and triamcinolone improves the structure outcome in patients with retinal vein occlusion, but the authors have stated that they have no priority in using a combination of the two drugs six months after treatment compared with other studies in which either of these drugs alone had been used to achieve their objective. The last part of this study was not consistent with our study, which can be due to the longer duration of follow-up, as well as the lack of monotherapy. Also, the structure of studied populations differed in the two groups that these differences can be effective (44). In the study of Ramazani et al., the results showed the better response to treatment in the group of IVB, so that our study showed the better response to treatment in the group of combined IVB and IVT, which was inconsistent with our results (22). But the results of the study of Jin et al., were consistent with our results and had the better outcome in the group of combined IVT and 
http://www.ephysician.ir

IVB (45). Wang et al., reported that there was no significant difference in terms of CRVO treatment using IVT and IVB, which was inconsistent with our results (46). There is still need for further studies in order to access additional information about the choice treatment for CRVO. Other limitations of the current study were the small sample of participants and performing in the single center.

\section{Conclusions}

In general it can be concluded that the combination of bevacizumab and triamcinolone had better effect in the treatment of CRVO compared to the use of them alone, and can be used as a solution in the treatment of this disease. We suggest that the solution of the bevacizumab and triamcinolone be made by pharmacology factories, but before that, future studies in a larger sample and in different populations may approve the results of our study.

\section{Acknowledgments:}

The authors appreciate the research chancellor of Urmia University of Medical Sciences which supported this study financially. This article is obtained from a medical student thesis by Dr. Miaad Rajabzadeh (approval number 94-0663-1815).

\section{Trial registration:}

The trial was registered at the Thai Registry of Clinical Trials (http://www.clinicaltrials.in.th) with the TCTR ID: TCTR20170612005.

\section{Funding:}

The authors received no financial support for the research, authorship, and/or publication of this article.

\section{Conflict of Interest:}

There is no conflict of interest to be declared.

Authors' contributions:

All authors contributed to this project and article equally. All authors read and approved the final manuscript.

\section{References:}

1) Rogers SL, McIntosh RL, Lim L, Mitchell P, Cheung N, Kowalski JW, et al. Natural history of branch retinal vein occlusion: an evidence-based systematic review. Ophthalmology. 2010; 117(6): 1094-1101.e5. doi: 10.1016/j.ophtha.2010.01.058. PMID: 20430447.

2) Klein R, Klein BE, Moss SE, Meuer SM. The epidemiology of retinal vein occlusion: the Beaver Dam Eye Study. Trans Am Ophthalmol Soc. 2000; 98: 133-41. PMID: 11190017, PMCID: PMC1298220.

3) McAllister IL. Central retinal vein occlusion: a review. Clin Exp Ophthalmol. 2012; 40(1): 48-58. doi: 10.1111/j.1442-9071.2011.02713.x. PMID: 22003973.

4) Coscas G, Loewenstein A, Augustin A, Bandello F, Battaglia Parodi M, Lanzetta P, et al. Management of retinal vein occlusion--consensus document. Ophthalmologica. 2011; 226(1): 4-28. PMID: 21577038.

5) Aiello LP, Avery RL, Arrigg PG, Keyt BA, Jampel HD, Shah ST, et al. Vascular endothelial growth factor in ocular fluid of patients with diabetic retinopathy and other retinal disorders. N Engl J Med. 1994; 331(22): 1480-7. doi: 10.1056/NEJM199412013312203. PMID: 7526212.

6) Pe'er J, Folberg R, Itin A, Gnessin H, Hemo I, Keshet E. Vascular endothelial growth factor upregulation in human central retinal vein occlusion. Ophthalmology. 1998; 105(3): 412-6. doi: 10.1016/S01616420(98)93020-2. PMID: 9499769.

7) Ng EW, Adamis AP. Targeting angiogenesis, the underlying disorder in neovascular age-related macular degeneration. Can J Ophthalmol. 2005; 40(3): 352-68. doi: 10.1016/S0008-4182(05)80078-X. PMID: 15947805 .

8) Noma H, Minamoto A, Funatsu H, Tsukamoto H, Nakano K, Yamashita H, et al. Intravitreal levels of vascular endothelial growth factor and interleukin-6 are correlated with macular edema in branch retinal vein occlusion. Graefes Arch Clin Exp Ophthalmol. 2006; 244(3): 309-15. doi: 10.1007/s00417-004-10874. PMID: 16133018.

9) Wilson CA, Berkowitz BA, Sato Y, Ando N, Handa JT, de Juan E Jr. Treatment with intravitreal steroid reduces blood-retinal barrier breakdown due to retinal photocoagulation. Arch Ophthalmol. 1992; 110(8): 1155-9. PMID: 1497531.

10) Bezatis A, Spital G, Hohn F, Maier M, Clemens CR, Wachtlin J, et al. Functional and anatomical results after a single intravitreal Ozurdex injection in retinal vein occlusion: a 6-month follow-up -- the SOLO study. Acta Ophthalmol. 2013; 91(5): e340-7. doi: 10.1111/aos.12020. PMID: 23638803. 
11) Joshi L, Tomkins-Netzer O, Menezo V, Sallam A, Kirkpatrick N, Lightman S, et al. Dexamethasone implants and neovascular glaucoma in central retinal vein occlusion. Acta Ophthalmol. 2013; 91(3): e23940. doi: 10.1111/aos.12009. PMID: 23241218.

12) Matonti F, Meyer F, Guigou S, Barthelemy T, Dumas S, Gobert F, et al. Ozurdex in the management of the macular edema following retinal vein occlusion in clinical practice. Acta Ophthalmol. 2013; 91(7): e584-6. doi: 10.1111/aos.12190. PMID: 23764276.

13) Nauck M, Karakiulakis G, Perruchoud AP, Papakonstantinou E, Roth M. Corticosteroids inhibit the expression of the vascular endothelial growth factor gene in human vascular smooth muscle cells. Eur $\mathrm{J}$ Pharmacol. 1998; 341(2-3): 309-15. PMID: 9543253.

14) Ramezani A, Entezari M, Moradian S, Tabatabaei H, Kadkhodaei S. Intravitreal triamcinolone for acute central retinal vein occlusion; a randomized clinical trial. Graefes Arch Clin Exp Ophthalmol. 2006; 244(12): 1601-6. doi: 10.1007/s00417-006-0348-9. PMID: 16738858.

15) Ip MS, Scott IU, VanVeldhuisen PC, Oden NL, Blodi BA, Fisher M, et al. A randomized trial comparing the efficacy and safety of intravitreal triamcinolone with observation to treat vision loss associated with macular edema secondary to central retinal vein occlusion: the Standard Care vs Corticosteroid for Retinal Vein Occlusion (SCORE) study report 5. Arch Ophthalmol. 2009; 127(9): 1101-14. doi: 10.1001/archophthalmol.2009.234. PMID: 19752419, PMCID: PMC2872173.

16) Algvere PV, Epstein D, von Wendt G, Seregard S, Kvanta A. Intravitreal bevacizumab in central retinal vein occlusion: 18-month results of a prospective clinical trial. Eur J Ophthalmol. 2011; 21(6): 789-95. doi: 10.5301/EJO.2011.6522. PMID: 21484753.

17) Campochiaro PA, Brown DM, Awh CC, Lee SY, Gray S, Saroj N, et al. Sustained benefits from ranibizumab for macular edema following central retinal vein occlusion: twelve-month outcomes of a phase III study. Ophthalmology. 2011; 118(10): 2041-9. doi: 10.1016/j.ophtha.2011.02.038. PMID: 21715011.

18) Epstein DL, Algvere PV, von Wendt G, Seregard S, Kvanta A. Bevacizumab for macular edema in central retinal vein occlusion: a prospective, randomized, double-masked clinical study. Ophthalmology. 2012; 119(6): 1184-9. doi: 10.1016/j.ophtha.2012.01.022. PMID: 22424833.

19) Heier JS, Campochiaro PA, Yau L, Li Z, Saroj N, Rubio RG, et al. Ranibizumab for macular edema due to retinal vein occlusions: long-term follow-up in the HORIZON trial. Ophthalmology. 2012; 119(4): 802-9. doi: 10.1016/j.ophtha.2011.12.005. PMID: 22301066.

20) Varma R, Bressler NM, Suner I, Lee P, Dolan CM, Ward J, et al. Improved vision-related function after ranibizumab for macular edema after retinal vein occlusion: results from the BRAVO and CRUISE trials. Ophthalmology. 2012; 119(10): 2108-18. doi: 10.1016/j.ophtha.2012.05.017. PMID: 22817833.

21) Zhang H, Liu ZL, Sun P, Gu F. Intravitreal bevacizumab for treatment of macular edema secondary to central retinal vein occlusion: eighteen-month results of a prospective trial. J Ocul Pharmacol Ther. 2011; 27(6): 615-21. doi: 10.1089/jop.2011.0050. PMID: 21823986.

22) Ramezani A, Esfandiari H, Entezari M, Moradian S, Soheilian M, Dehsarvi B, et al. Three intravitreal bevacizumab versus two intravitreal triamcinolone injections in recent onset central retinal vein occlusion. Acta Ophthalmol. 2014; 92(7): e530-9. doi: 10.1111/aos.12317. PMID: 24373344.

23) Abdelghany AI, Mahmoud M, Alazab EA, Ghazy MI, Abdallah MA. Prospective study of single intravitreal triamcinolone acetonide versus bevacizumab for treatment macular edema secondary to branch retinal vein occlusion. AAMJ. 2011; 9(2): 68-80.

24) Priglinger SG, Wolf AH, Kreutzer TC, Kook D, Hofer A, Strauss RW, et al. Intravitreal bevacizumab injections for treatment of central retinal vein occlusion: six-month results of a prospective trial. Retina. 2007; 27(8): 1004-12. doi: 10.1097/IAE.0b013e3180ed458d. doi: 10.1097/IAE.0b013e3180ed458d. PMID: 18040236.

25) Astam N, Batioglu F, Ozmert E. Short-term efficacy of intravitreal bevacizumab for the treatment of macular edema due to diabetic retinopathy and retinal vein occlusion. Int Ophthalmol. 2009; 29(5): 343-8. doi: 10.1007/s10792-008-9242-2. PMID: 18553061.

26) Costa RA, Jorge R, Calucci D, Melo LA Jr., Cardillo JA, Scott IU. Intravitreal bevacizumab (avastin) for central and hemicentral retinal vein occlusions: IBeVO study. Retina. 2007; 27(2): 141-9. doi: 10.1097/IAE.0b013e31802eff83. PMID: 17290194.

27) Badala F. The treatment of branch retinal vein occlusion with bevacizumab. Curr Opin Ophthalmol. 2008; 19(3): 234-8. doi: 10.1097/ICU.0b013e3282fb7fb0. PMID: 18408499.

28) Soheilian M, Ramezani A, Bijanzadeh B, Yaseri M, Ahmadieh H, Dehghan MH, et al. Intravitreal bevacizumab (avastin) injection alone or combined with triamcinolone versus macular photocoagulation as 
primary treatment of diabetic macular edema. Retina. 2007; 27(9): 1187-95. doi: 10.1097/IAE.0b013e31815ec261. PMID: 18046223.

29) Tao Y, Hou J, Jiang YR, Li XX, Jonas JB. Intravitreal bevacizumab vs triamcinolone acetonide for macular oedema due to central retinal vein occlusion. Eye (Lond). 2010; 24(5): 810-5. doi: 10.1038/eye.2009.220. PMID: 19696805.

30) Noma H, Funatsu H, Yamasaki M, Tsukamoto H, Mimura T, Sone T, et al. Pathogenesis of macular edema with branch retinal vein occlusion and intraocular levels of vascular endothelial growth factor and interleukin-6. Am J Ophthalmol. 2005; 140(2): 256-61. doi: 10.1016/j.ajo.2005.03.003. PMID: 16086947.

31) Gillies MC, Simpson JM, Billson FA, Luo W, Penfold P, Chua W, et al. Safety of an intravitreal injection of triamcinolone: results from a randomized clinical trial. Arch Ophthalmol. 2004; 122(3): 336-40. doi: 10.1001/archopht.122.3.336. PMID: 15006845.

32) Jonas JB, Kreissig I, Degenring R. Intraocular pressure after intravitreal injection of triamcinolone acetonide. Br J Ophthalmol. 2003; 87(1): 24-7. PMID: 12488256, PMCID: PMC1771462.

33) Lau LI, Chen KC, Lee FL, Chen SJ, Ko YC, Liu CJ, et al. Intraocular pressure elevation after intravitreal triamcinolone acetonide injection in a Chinese population. Am J Ophthalmol. 2008; 146(4): 573-8. doi: 10.1016/j.ajo.2008.05.034. PMID: 18639860.

34) Smithen LM, Ober MD, Maranan L, Spaide RF. Intravitreal triamcinolone acetonide and intraocular pressure. Am J Ophthalmol. 2004; 138(5): 740-3. doi: 10.1016/j.ajo.2004.06.067. PMID: 15531307.

35) Hsu J, Kaiser RS, Sivalingam A, Abraham P, Fineman MS, Samuel MA, et al. Intravitreal bevacizumab (avastin) in central retinal vein occlusion. Retina. 2007; 27(8): 1013-9. DOI: 10.1097/IAE.0b013e318050ca7c. PMID: 18040237.

36) Iturralde D, Spaide RF, Meyerle CB, Klancnik JM, Yannuzzi LA, Fisher YL, et al. Intravitreal bevacizumab (Avastin) treatment of macular edema in central retinal vein occlusion: a short-term study. Retina. 2006; 26(3): 279-84. PMID: 16508427.

37) Rosenfeld PJ, Fung AE, Puliafito CA. Optical coherence tomography findings after an intravitreal injection of bevacizumab (avastin) for macular edema from central retinal vein occlusion. Ophthalmic Surg Lasers Imaging. 2005; 36(4): 336-9. PMID: 16156153.

38) Spandau UH, Ihloff AK, Jonas JB. Intravitreal bevacizumab treatment of macular oedema due to central retinal vein occlusion. Acta Ophthalmol Scand. 2006; 84(4): 555-6. doi: 10.1111/j.16000420.2006.00740.x. PMID: 16879582.

39) Bhisitkul RB. Vascular endothelial growth factor biology: clinical implications for ocular treatments. Br J Ophthalmol. 2006; 90(12): 1542-7. doi: 10.1136/bjo.2006.098426. PMID: 17114590, PMCID: PMC1857529.

40) Gillies MC. What we don't know about avastin might hurt us. Arch Ophthalmol. 2006; 124(10): 1478-9. doi: 10.1001/archopht.124.10.1478. PMID: 17030717.

41) Schlingemann RO. Role of growth factors and the wound healing response in age-related macular degeneration. Graefes Arch Clin Exp Ophthalmol. 2004; 242(1): 91-101. doi: 10.1007/s00417-003-0828-0. PMID: 14685874.

42) Cunningham ET Jr, Adamis AP, Altaweel M, Aiello LP, Bressler NM, D'Amico DJ, et al. A phase II randomized double-masked trial of pegaptanib, an anti-vascular endothelial growth factor aptamer, for diabetic macular edema. Ophthalmology. 2005; 112(10): 1747-57. doi: 10.1016/j.ophtha.2005.06.007. PMID: 16154196.

43) Ekdawi NS, Bakri SJ. Intravitreal triamcinolone and bevacizumab combination therapy for macular edema due to central retinal vein occlusion refractory to either treatment alone. Eye (Lond). 2007; 21(8): 1128-30. doi: 10.1038/sj.eye.6702903. PMID: 17585312 .

44) Ehrlich R, Ciulla TA, Moss AM, Harris A. Combined treatment of intravitreal bevacizumab and intravitreal triamcinolone in patients with retinal vein occlusion: 6 months of follow-up. Graefes Arch Clin Exp Ophthalmol. 2010; 248(3): 375-80. doi: 10.1007/s00417-009-1211-6. PMID: 19898827.

45) Jin E, Luo L, Bai Y, Zhao M. Comparative effectiveness of intravitreal bevacizumab with or without triamcinolone acetonide for treatment of diabetic macular edema. Ann Pharmacother. 2015; 49(4): 387-97. doi: 10.1177/1060028014568006. PMID: 25622852.

46) Wang HY, Li X, Wang YS, Zhang ZF, Li MH, Su XN, et al. Intravitreal injection of bevacizumab alone or with triamcinolone acetonide for treatment of macular edema caused by central retinal vein occlusion. Int $\mathrm{J}$ Ophthalmol. 2011; 4(1): 89-94. doi: 10.3980/j.issn.2222-3959.2011.01.21. PMID: 22553618, PMCID: PMC3340676. 